\title{
REPRESENTAÇÕES DA EDUCAÇÃO KARAJÁ
}

\author{
M ARCUS M AIA*
}

RESU M 0: Este artigo relata e analisa diferentes conjuntos de representações discursivas sobre a educação bilíngüe Karajá produzida por professores indígenas, lideranças e anciãos Karajá, bem como funcionários da Funai e missionários com atuação na área com o objetivo de contribuir para a compreensão da escola K arajá.

Palavras-chave: Educação indígena; Educação bilíngüe; Discurso indígena; Karajá; J avaé.

\section{Introdução}

Este artigo analisa representações discursivas sobre a educação bilíngüe Karajá, sociedade indígena brasileira composta por cerca de 3.000 pessoas que habitam nove aldeias principais ao longo do rio A raguaia, nos estados de Tocantins, Goiás e $M$ ato Grosso. A pesquisa iniciou-se em julho de 1988, quando os então pesquisadores do M useu do Índio (Funai-RJ) M arcus Antonio Rezende M aia e Carlos Alberto M ontes de Peres, responsáveis pela execução do projeto de pesquisa "D ocumentação e Análise de Programas e Projetos de Educação Indígena", patrocinado pelo IN EP-M E, visitaram as aldeias Karajá de Santa Isabel do M orro, Barra do Tapirapé, M acaúba e Aruanã com o objetivo de colher informações primárias junto a professores, monitores bilíngües e programadores educacionais atuantes em programas e projetos de educação na área Karajá, bem como junto aos próprios alunos, ex-alunos e demais membros da comunidade indígena. Dez anos após a pesquisa inicial, entre setembro de 1997 e outubro de 1998, o autor do presente artigo revisitou várias das aldeias participantes do estudo original, avaliando e complementando os dados coletados em 1988. Entre 1988 e 1998, um programa de educação, ligado à Funai e apoiado pelo

* $\quad$ Professor Adjunto de Lingüística do D epartamento de Antropologia do M useu Nacional, da Universidade Federal do Rio de Janeiro (UFRJ). E-mail: marcusmaia@alternex.com.br 
M inistério da Educação com a participação de lingüistas e pedagogos, incluindo 0 autor deste artigo, vem realizando intervenções sistemáticas na educação bilíngüe Karajá. 0 presente artigo avalia a situação educacional dos Karajá anteriormente a essas intervenções, que serão objeto de estudo posterior. N ote-se, entretanto, que as vozes que aqui se ouvirão, embora originalmente registradas há uma década, ainda ecoam fortemente no presente. O uvi-las com atenção certamente contribuirá para nossa atuação presente e futura junto aos Karajá.

Ressalte-se desde logo que se abandonou neste estudo qualquer enfoque de natureza quantitativa que não tivesse relevância imediata para a análise. C onsiderou-se que a adoção de uma perspectiva analítica predominantemente interpretativista (e não tanto descrivista ou historicista) seria o procedimento epistemológico mais adequado para se reportar 0 material coletado em campo, constituído, fundamentalmente, por impressões, opiniões e pareceres de grande relevo para a compreensão da Escola Karajá, mas de natureza dificilmente quantificável.

N este sentido, procurou-se montar neste artigo um amplo "painel polifônico" que, ao mesmo tempo que resgatasse as "vozes" ouvidas pelos pesquisadores no campo, pudesse fornecer ao leitor um retrato vivo, interessado e fiel da escola Karajá. Ainda que a escolha dos "personagens" e de suas "falas" tenha sido, até certo ponto, inevitavelmente determinada pelos sistemas de crenças dos autores, pretende-se que as principais categorias recorrentes nos diversos discursos tenham sido adequadamente explicitadas. Buscou-se, assim, iluminar as pressuposições básicas subjacentes às muitas falas, em um esforço para encontrar os alcances e os limites da Escola Karajá a partir de concepções internas, inerentes aos seus próprios sujeitos - a comunidade indígena e as agências educacionais presentes na área Karajá.

\section{M etodologia}

Este estudo objetiva analisar diferentes discursos constitutivos da entidade que estamos chamando de Escola K arajá. Q ueremos nesta seção explicitar os pressupostos metodológicos da pesquisa, bem como aspectos da própria metodologia que são relevantes não só para revelar a fundamentação da pesquisa, mas também para permitir a compreensão adequada do artigo.

I nicialmente, é necessário delimitar o conceito "Escola Karajá". Estamos focalizando aqui, exclusivamente, o que Bartolomeu M elia ${ }^{1}$ denomina de Educação para o indígena e não os sistemas tradicionais de 
transmissão de conhecimento utilizados internamente pela sociedade indígena, independentemente de suas relações com a sociedade envolvente.

O s dados foram coletados em campo em entrevistas com base em formulários especificamente organizados para a pesquisa. Esses formulários buscavam elicitar informações sobre os diferentes aspectos da Escola $K$ arajá. O s pesquisadores procuraram, no entanto, ser suficientemente flexíveis na condução das entrevistas, de forma a incorporar outros tópicos aventados pelos informantes e a permitir que estes discorressem com liberdade sobre os temas que julgassem de maior relevo. Este procedimento coaduna-se com o objetivo de se levantar e analisar as representações constitutivas da Escola Karajá, a partir de categorias discursivas internas, como evidenciamos acima, e não com base em critérios externos.

\section{Histórico da Pesquisa de Campo}

0 período escolhido para a visita às aldeias, julho/agosto de 1988, foi 0 da realização de um programa de reciclagem pedagógica na aldeia Karajá de Santa Isabel do M orro, na Ilha do Bananal, quando cerca de 15 professores bilíngües indígenas e 5 professoras não-indígenas atuantes em oito aldeias Karajá e Javaé reuniram-se durante duas semanas para participar de cursos nas áreas de Língua (Português e Karajá), Estudos Sociais e M atemática. 0 autor do presente artigo, o pesquisador $M$ arcus $M$ aia, foi convidado pela 6 a Superintendência Regional para a coordenação geral do programa, bem como para conduzir as atividades da área de Linguagem. Para conduzir a programação de Estudos Sociais, convidouse 0 antropólogo André Toral, que atua junto aos Karajá e Javaé desde 1975. A parte de M atemática ficou a cargo do professor Francisco Roberto Vieira, da Universidade Federal Fluminense.

N ote-se que, à exceção da professora da aldeia Javaé de Boto Velho, todos os demais professores foram direta ou indiretamente formados pelo Instituto Lingüístico de Verão (SIL), organização missionária norteamericana que, em 1971, iniciou na aldeia de M acaúba o projeto piloto do Programa de Educação Bilíngüe e Bicultural (Peba) do Araguaia, a partir da experiência do casal de lingüistas $D$ avid e $G$ retchen Fortune, que desde 1958 já desenvolvia pesquisa lingüística junto aos Karajá. A partir de 1971 o casal Fortune torna-se responsável pela seleção e treinamento de professores, metodologia e produção de material didático para as escolas Karajá.

Como em 1988 não vigia qualquer acordo de cooperação oficial entre a Funai e o SIL, foi possível organizar-se pela primeira vez um 
programa de reciclagem pedagógica para os professores Karajá sem a ingerência do SIL. D esta forma, o encontro de professores Karajá de 1988 seria um momento atípico na história da Educação Karajá: pela primeira vez reunia-se uma equipe coordenada pela Funai, incluindo profissionais ligados a instituições universitárias brasileiras com qualificação para assessorar a Escola Karajá.

Em uma reunião preparatória do Curso em maio do mesmo ano, em Goiânia, a programadora educacional da 6a Superintendência da Funai havia reportado ao coordenador do programa a necessidade de se produzirem novos materiais didáticos para uso nas escolas Karajá, uma vez que o material originalmente produzido pelo SIL encontrava-se praticamente esgotado. Assim, foi estabelecido que os professores responsáveis pelas três disciplinas organizariam durante o curso uma espécie de "oficina" em que os próprios professores Karajá redigiriam os materiais que fossem necessários em cada área. 0 M useu do Índio ficaria encarregado da editoração e impressão dos livros didáticos. Posteriormente, estes materiais seriam editados em conjunto com a Imprensa O ficial do Município do Rio de Janeiro.

Enquanto desdobravam-se os preparativos para a realização da viagem à campo, foi aventada a possibilidade de se realizar um documentário em vídeo sobre a Escola Karajá. Através do D epartamento de Análise M atemática da U niversidade Federal Fluminense, que já vinha desde 1986 assessorando o Projeto de Educação Bilíngüe da aldeia Javaé de Boto Velho, ${ }^{2}$ elaborou-se um convênio entre o N úcleo Audio-Visual da Universidade (N AV-UFF) e o M useu do Índio, com vistas à realização do projeto. O N AV-UFF cedeu o equipamento e designou dois profissionais para a viagem, o professor Luiz Edmundo Silva e o fotógrafo Juliano Serra. 0 M useu do Indio responsabilizou-se pelas passagens aéreas e pelas diárias de um dos técnicos da UFF na área Karajá, além de haver adquirido as fitas VH S para o registro das imagens. D ocumentaram-se, assim, em vídeo, cerca de 24 horas de imagens sobre diferentes aspectos da Escola Karajá, tendo-se entrevistado todos os professores indígenas presentes ao curso de Santa I sabel, lideranças Karajá, alunos e ex-alunos de diversas escolas Karajá, além de tecnicos da Funai, membros do Instituto de Verão e do Consel ho Indigenista M issionário - Cimi, com atuação junto aos Karajá.

O utro projeto realizado concomitantemente pelo Setor de Antropologia V isual do M useu do Índio e que foi implementado na aldeia de Santa Isabel com 0 apoio de toda a equipe foi a exposição fotográfica intitulada "M emória Karajá", expondo-se na aldeia fotos feitas sobre os 
Karajá nas décadas de 1950 e 1960. Registre-se que todos estes eventos, bem como diversas cenas do cotidiano dos Karajá, foram documentadas em vídeo e eram regularmente apresentadas à comunidade indígena em sessões noturnas na aldeia, que dispõe de aparelho deTV para uso coletivo.

Foi também apresentado aos Karajá nestas sessões o material previamente gravado pela equipe no M useu N acional (U FRJ), no M useu Antropológico da Universidade Federal de Goiás e no M useu do Índio. No M useu N acional entrevistaram-se a professora H eloísa Fenelon, especialista em arte Karajá e o pesquisador $\mathrm{H}$ amilton Botelho. Foi filmada ainda parte do acervo Karajá daquela instituição. No M useu Antropológico, em Goiânia, entrevistou-se a professora Silvia Braggio, especialista em Educação Indígena e filmou-se também o material Karajá, em poder daquela Instituição. No M useu do Índio, gravou-se entrevista com a antropóloga Cláudia M enezes, diretora do M useu, que fez breve exposição aos Karajá sobre os objetivos dos projetos que a equipe do M useu coordenaria na área Karajá. No Rio de Janeiro, a equipe entrevistou também 0 escritor João Américo Peret, ex-funcionário do extinto Serviço de Proteção aos Índios, que trabalhou durante muitos anos entre os Karajá.

Também entrevistaram-se dois importantes líderes do povo Karajá que moram presentemente fora do Parque Indígena do Araguaia, mas que se encontravam na aldeia de Santa I sabel na ocasião. I jahuri Karajá, ex-aluno do Programa de Ensino Bilíngüe (Peba) coordenado pelo Instituto Lingüistico de Verão, ex-candidato a deputado Federal pelo PM D B, era na ocasião responsável pela Superintendência de Assuntos Indígenas do Governo do Estado de G oiás, onde buscava articular diferentes programas de apoio aos grupos indígenas de Goiás, entre os quais um programa de educação bilíngüe projetado em colaboração com a professora Silvia Braggio, da U niversidade Federal de Goiás. Kurehetxi Karajá, também ex-aluno do Peba, ocupava então o cargo de assessor da Presidência da Funai. N este período, além das entrevistas realizadas entre os Karajá, a equipe entrevistou, na cidade de São Félix do Araguaia, 0 bispo D om Pedro Casaldáliga, do Cimi, e o pastor D onatilo Fonseca da M issão Adventista do Araguaia.

Após o término do curso, os pesquisadores e os técnicos do N AVUFF desceram o rio Araguaia em barco da comunidade indígena Karajá de Barra do Tapirapé e M acaúba, onde se realizaram novas entrevistas e documentou-se uma aula do professor Joel Wahuri às crianças da Aldeia de Barra do Tapirapé; visitou-se também a aldeia dos índios Tapirapé, onde se entrevistaram as irmãzinhas de Jesus, missionárias não-fundamentalistas que trabal haram com os Karajá antes da chegada dos evan- 
gélicos fundamentalistas da M issão N ovas Tribos e do Instituto Lingüístico de Verão. $\mathrm{N}$ a cidade de Santa Terezinha, próxima a aldeia de M acaúba, entrevistou-se o casal Luiz e Eunice G ouvêa, que coordenam há vários anos projeto educacional ligado ao Cimi junto aos índios Tapirapé.

Finalmente, parte da equipe dirigiu-se à Braślia para realização de entrevistas na sede nacional do Instituto Lingüistico de Verão, enquanto o pesquisador $\mathrm{M}$ arcus $\mathrm{M}$ aia viajava à aldeia de Aruanã, ao sul da Ilha do Bananal, com vistas a observar a situação educacional daquela aldeia, onde não há sistema escolar específico para os Karajá.

A pesquisa aqui reportada situou-se, portanto, em um contexto mais amplo, bastante produtivo. Se, por um lado, os executantes diretos do projeto precisaram dividir a sua atenção com os demais projetos que se realizavam paralelamente à pesquisa, estes outros projetos permitiram, por outro lado, que se ampliasse e aprofundasse, em muitos aspectos, o escopo original da pesquisa. Não fosse o curso da aldeia de Santa Isabel, dificilmente teria se tido acesso aos professores das oito aldeias Karajá e Javaé ali presentes; não fosse o projeto de vídeo em conjunto com a U FF, não se teria tido meios para registrar de forma tão expressiva os diversos depoimentos e entrevistas utilizados nesta pesquisa.

\section{A Escola Karajá: a concepção dos professores indígenas}

Foram feitas duas entrevistas com os professores indígenas ${ }^{3}$ presentes ao curso de reciclagem pedagógica promovido pela Funai na aldeia de Santa I sabel do M orro, nas duas últimas semanas de julho de 1988. A primeira, individual, foi registrada em gravador cassete. Focalizava, fundamentalmente, os seguintes tópicos: formação do professor, o ensino bilíngüe, objetivos da Escola Karajá, principais dificuldades encontradas pelos professores. A segunda série de entrevistas reuniu os professores por aldeia, tendo sido gravada em vídeo. Abordaram-se aí, além dos tópicos acima, questões de natureza mais geral muitas vezes aventadas pelos próprios professores, tais como necessidades das aldeias, preocupações em relação a recursos, assistência da Funai etc. Anal isaremos abaixo as categorias recorrentes nas falas dos professores, agrupando-as em termos dos tópicos focalizados nas entrevistas. $\mathrm{N}$ ote-se que, embora reconheçamos a existência de diferenças individuais entre as escolas das várias aldeias consideradas, não avaliamos como pertinente para os fins da presente pesquisa a explicitação dessas diferenças. 


\section{A) A formação dos professores}

A análise das representações dos monitores sobre sua própria formação permite o levantamento de algumas categorias recorrentes elucidativas da própria concepção de educação e de escola entre os Karajá. O s professores são unânimes em reconhecer a dificuldade que encontraram em sua própria alfabetização, que se deu em língua portuguesa e teve lugar em escola municipal ou ligada a missão evangélica. A dificuldade de compreensão da língua portuguesa é apontada por quase todos como a principal causa dos problemas de aprendizagem. A fala do monitor de Barra do Tapirapé é paradigmática:

0 estudo naquela época era diretamentena língua portuguesa... N essa época não tinha ensino bilíngüe. Eu achei muito difícil porque não entendia português. (Joel Wahuri Karajá)

Reconhecendo a dificuldade para alfabetizarem-se na língua portuguesa, os professores acentuam por um lado o esforço que lhes foi exigido para transpor a barreira lingüística e, por outro, a importância do ensino bilíngüe. A alfabetização em português tem 0 caráter de verdadeiro rito de passagem: é a prova exigida para se ter direito de tentar a decifração do mundo "tori" (não índio):

Eu comecei aestudar com professor nacional, masfoi tão difícil porquenaqueles temposeu não estavanem aprendendo afalar português. Estudei com professora nacional até que alfabetizei com a maior dificuldade, aprendi português e aprendi as coisas. (Valdemir I xerua Javaé)

Aprender português oral e, principalmente, alfabetizar-se nesta língua é 0 instrumento que permite "melhorar de vida". Note-se que este "salto qualitativo" está crucialmente relacionado à distância que separa uma cultura ágrafa da civilização letrada:

Q uando eu comecei entrando na escolanão entendianada o quea letra valia. Aí eu cuidei da minhavida, praver semelhorava a minha vida. Estudei, estudei, atéqueentendi um pouco. (Raimundo Alàriki)

A barreira a ser transposta não pode portanto ser minimizada. $\mathrm{N}$ ote-se que os professores são aqueles que, em princípio, melhor realizaram esta passagem em cada al deia. A fala dos professores não deixa dúvida sobre a grandeza do esforço:

0 fundador da cidade de Luciara tem umafilha eela mechamou eperguntou seeu podia estudar, eu tinha dez anos. Aí, falei: "a vontadeémuita. Eu preciso 
estudar meu povo todo, até agora ninguém quase estudou e eu quero estudar como branco aprende as coisas." Eu queria aprender. Foi difícil, levou dois anos, foi difícil. (Paulo Kuadi)

Aí comecei a estudar na escola da M issão Adventista, em Português. M as eu não entendia o que a professora falava. Ela entregava o caderno para mim, prá acompanhar o gesto dela, ver como escrevia. Tava difícil deaprender Português, como équeeu ía responder?D epois eu acabei passando, mas acho queeu levei cinco ou seisanos só na primeira série. (D avi K rumare)

Encerrado o período escolar, quase sempre em torno da quarta série do primeiro grau, o rapaz, em regra, juntava-se às atividades produtivas da comunidade (pesca e roça) ou, com alguma sorte, obtinha emprego junto a Funai. É nesse momento que, geralmente, "aparecia" o professor D avi (D avid Fortune, lingüista do SIL), convocando-o para o curso que iria torná-lo monitor bilíngüe:

Estudei atéaquarta série, depoiseu casei, aí parei de estudar efui esquecendo. Aí quando peguei o curso para ser monitor efui aprendendo maise atéagora. (D aniel 0 hòri)

Aí, quando eu fiza terceira série, parei deestudar. Fiquei sem escola dois anos. Então o professor D avi apareceu. Eu estava trabal hando para a Funai, eu era rapazinho eeleapareceu emechamou. Eu fui no curso lá em M acaúba eestou atéagora como monitor. (Paulo K rumare)

o "aparecimento do professor D avi" é concebido como uma categoria quase mágica, um evento de caráter providencial que vem premiar 0 esforço empreendido na alfabetização:

Eu saí da escola efiquei aqui fazendo lavoura. D epois quando passou aquele serviço eu fiquei parado, eu vivia assim, pescando. Também eu tinha casado e sustentava meu filho e minha mulher através da pescaria. U m dia, eu estava pescando equando cheguei da pescaria, o professor $D$ avi estavana beira do rio meesperando. Aí, elefalou comigo. Então, eu fui láem casa enem almocei. Fui logo com ele prá fazer o teste prá ver quem dava conta de fazer o curso de monitor. (M arvel Tuila)

0 curso de formação de monitores bilíngües, conforme representado no discurso dos professores, se reveste de características de novo ritual de passagem, com rigores como 0 afastamento da família, a dificuldade dos testes. Dificuldades que nem todos ultrapassariam. É também nesses cursos organizados pelo SIL que os professores completarão sua aprendizagem dos conteúdos geralmente transmitidos no primeiro ciclo do primeiro grau: 
Eu passei quatro meses lá, fazendo o curso. M uitos desistiram, porque não conseguiram mesmo. D e vez em quando eu vinha ver como minha mulher estava passando na minha aldeia, mas voltava logo. (M arvel Tuila)

O professor D avi chegou láem Kanoano, conversou, convidou para o curso de monitor bilíngüena al deiadeM acaúba. Q uatro meses ensinando como éque a gente dá aula, como éque escreve no quadro, letra bem bonita prá criança entender. Como é que a gente faz os números, as contas. Foi bom, deu pra aprender muitacoisa. (M anoel M aruaja)

É nestes cursos que o Instituto de Verão introduz a proposta de ensino na língua Karajá. Para quase todos os professores será o primeiro contato com a escrita Karajá estabelecida pelos lingüistas do Instituto:

Gostei muito do curso, mas achei muito difícil porqueera com respeito à língua maternaeeu achei muito difícil porquena épocaqueeu estudava não estudava a línguaK arajá. Achei difícil, no começo não sabia ler enem escrever em K arajá. Fui pegando prática atéque aprendi. (Joel Wahuri)

O s cursos de formação de monitores do SIL conferiram um novo status social àqueles que conseguiram realizá-lo. O s professores reconhecem unanimemente a importância do curso em suas vidas, crêem que 0 Peba trouxe resultados positivos para o povo Karajá, avaliando este resultado em termos do sucesso que alguns índios têm alcançado junto à sociedade não-indígena:

N ós ficamos fazendo o curso durante quatro meses. Primeiro em M acaúba, depoisem Santal sabel eo terceiro curso foi em C anoanã, ondenosformamos. Fizemos tudo num grande afeto, veio o presidente da Funai, veio tudo e até agora a gente trabal ha no bilíngüe. Também achei que nós tivemos muito resultado, porque todos os alunos dos monitores quevocêsjá viram, o ljahuri, jáéassessor do governo de Goiás, o Kurehetxi trabal ha na Funai. Então, com isso, eu acho quenósjátemosum grande resultado. (Raimundo Àlariki)

\section{B) 0 ensino bilíngüe}

A introdução pelo Instituto de Verão da alfabetização em Karajá é considerada por todos os professores indígenas um grande avanço em relação à sua própria experiência de alfabetização em língua portuguesa:

0 importante é que a gente ensina na própria língua porque as crianças entendem muito mais fácil. Antigamente não era assim. Antigamente era professora nacional que ensinava pra criança quenão sabia nem falar língua 
deTori. Era difícil de aprender, demorava pra aprender. Agora tá mais fácil entender. (Paulo Krumare)

Alfabetização inicial em Karajá e em seguida a "transição" para o Português, como objetivo principal. N o discurso dos professores, o ensino da língua materna é representado como facilitador, como ponte para o ensino do Português, e não por algum valor intrínseco:

0 português, principalmente, éque leva a gente mais pra frente. N ós vamos aprendendo a escrita em nossa própria língua eentão agente vai passando para o Português, queéimportante. (Paulo Kuadi)

A transição é também concebida como um momento especialmente difícil, por diferentes razões: a dificuldade de aprendizagem do Português oral, a tendência a projetar 0 alfabeto Karajá no Português. É interessante observar que a língua portuguesa é, geralmente, representada como "mais difícil" do que a língua Karajá, em função da existência de traços gramaticais que, embora igualmente existentes em Karajá, são percebidos como características exclusivas do Português. A tradição de ensino do Português geralmente enfatiza a explicitação da gramática como parte da aprendizagem da língua, induzindo à associação inadequada entre categorias gramaticais, na verdade, universais, e a língua portuguesa exclusivamente.

Primeira coisa éaprender Karajá, queele (o aluno) já sabe através da mãe, da família, masaí aprendea escrever na escola. Português, elessó estão aprendendo (a falar) com oito, nove anos, então fica difícil a alfabetização em Português. (M arvel Tuila)

Principalmente, quando éno primeiro ano quetá passando parao Português, começando a escrever, jálêtudo misturado, já mistura letra Karajá com letrado Português, já é meio difícil. A gente, como sabe duas línguas, explica bem direitinho para os alunos compreender melhor. (Paulo Kuadi)

H oje, a dificuldade maior é a transição para o Português porque a língua portuguesaémuito difícil porquetem verbo, conjugação, tem passado, presente... (Joel Wahuri)

\section{C) Objetivos da Escola Karajá}

Embora um dos principais objetivos da equipe do Instituto de Verão, responsável pelo Peba, fosse a implementação de uma "ponte cultural" que pudesse ser atravessada em "ambas as direções", ${ }^{4}$ a representação, que se depreende do discurso dos professores indígenas a respeito 
das finalidades da Escola Karajá, é a de que esta deve visar proritariamente a instrumentalizar os K arajá para compreender e, eventualmente ingressar no mundo não-indígena.

Tem que aprender a ler e a escrever em Português prá melhorar a vida. D a minha parte, eu antigamente, não tinha nada para dar assistência à minha esposa, aí precisava pescar, botar roça, sofri muito... M as depois que eu fizo curso práser monitor eu já comprei muitas coisas pra mim eminhaesposa. Eu estou trabalhando para aFunai, já ganho direito, ai tenho condições deter uma casa bem arrumada. Eu falo sempre prás crianças pra ir à escola, aprender muitas coisas queédo branco, como vocês estão trabalhando, pratrabalhar no escritório ou mesmo na sede da Funai. (Raimundo Alàriki)

A escola é, portanto, o lugar onde se aprende a cultura do "branco". Interessa conhecer os valores da sociedade envolvente para "melhorar de vida", adquirindo bens e valores do mundo não-indígena porque:

...hoje em dia a gente vai vivendo só com o dinheiro mesmo, sabe? Porque ninguém dá, assim, de presente. Então, por isso, a gente quer aprender prá ganhar trabalho, dinheiro. (Paulo Krumare)

0 índio quer aprender a ler eescrever para conhecer maiso sistema dos brancos. $\mathrm{N}$ a cartilha bilíngüe tem a palavra em Karajá e embaixo tem o Português. Interessa maiséaprender o Português. (Julio Làkukui)

Paradoxalmente, aprender a vida do "branco" não significa necessariamente deixar de ser índio. $\mathrm{H}$ á na representação dos professores 0 ideal vivo do equilíbrio entre culturas. N este sentido, há uma "voz" que defende a preservação dos valores próprios dos Karajá e concebe o papel da escola como sendo o de permitir comprender o mundo do "branco" para garantir 0 mundo do índio. De qualquer forma, a educação escolar é sempre concebida como reveladora do mundo não-indígena.

A importância é que sempre vem chegando a civilização no nosso meio e a importânciaéa gente saber mais prá poder semanter. Por exemplo, saber o que acontececom a nova Constituição, que quer acabar com o índio. Então, nós temosqueficar sabendo práenfrentar enão prádeixar deser o quenós somos. (Joel Wahuri)

Esta voz preservacionista está presente na fala de todos os professores Karajá. M esmo quando alguns concebem, como Raimundo Alàriki, acima, que melhorar de vida é possuir bens e valores do mundo nãoindígena, não se ouve jamais no discurso dos professores nenhuma "voz" explicitamente integracionista. 0 próprio Alàriki afirma: 
Tem unstori quejátem falado prá genteacompanhar só a vida do branco agora. Tem unsKarajáquejá pensa em deixar anação, mas eu pra mim, eu não tenho interessenisso. Eu tenho interesseem entender o queédo branco, mas não prá deixar a nossa nação. (Raimundo Alàriki)

$\mathrm{N}$ ão fica claro na fala dos professores, no entanto, como conciliar, na prática, estes dois objetivos - 0 de aprender os valores do "branco" e o de continuar a ser Karajá. 0 que fica bastante claro, por outro lado, é a concepção de que a escola , como afirmamos acima, serve basicamente para apresentar conhecimentos pertencentes ao mundo não-indígena. N este sentido, um professor vocaliza mesmo a existência de pressões, por parte de muitas famílias, no sentido de que 0 ensino deixe de ser bilíngüe, voltando-se exclusivamente para o ensino do Português:

N esse tempo agora está ruim porque os pais estão sendo contra nós, poque acham queo ensino bilíngüe está levando as criançadas para trás. D izem que não estão aprendendo nada, só a língua K arajá, que já sabem. Q uerem que ensinem só em Português. M uitos até proíbem as crianças de vir prá escola. (D avi Krumare)

De modo geral, os professores indígenas reagem a esta descaracterização da filosofia do ensino bilíngüe-bicultural em que foram formados. M uitos se esforçam para fazer da escola a ponte de "mão dupla" da concepção original do Peba, mas reconhecem não ser esta a vocação primária da escola, com o máximo, a cultura Karajá é abordada no âmbito da escola, com o sentido de, contrastivamente, facilitar a percepção dos valores externos, que ali são mediados pelos professores indígenas:

Àsvezes, faço reunião com os paise com as mães também porquea gentenão podedeixar o quenós somos. As criançastem queaprender as coisas dosK arajás antigosedosTori também. (D avi K rumare)

D e vez em quando eu falo das culturas nossas Karajá, como éa diferença da cultura Tori. É muito diferente da nossa. Eu falo prá eles sobre alimento, pescaria, muitas coisas. 0 branco tem cultura enós também. Assim éque eu explico prás crianças. (Paulo Kuadi)

Assim, como está patente no discurso dos professores indígenas, a Escola Karajá parece refletir de fato a ambigüidade característica da situação de contato em que se encontra esta sociedade: por um lado, a forte penetração da sociedade dita "civilizada", com seus atrativos por vezes irresistíveis, impondo a sua decifração sob a ameaça de "engolir" os Karajá. 
Por outro lado, a cultura tradicional Karajá que, paradoxalmente, precisa "conhecer" a cultura envolvente para garantir a sua sobrevivência, mas que neste processo pode ser por ela engolfada. Esta possibilidade que se afigura bastante real quando se observam aldeias mais períficas, tais como Aruanã, ao sul da Ilha do Bananal, ou Xambioá, ao norte, onde não se praticam mais as festas tradicionais e a língua Karajá não é mais falada pelas crianças, não parece estar expressa de forma suficientemente clara entre as preocupações dos professores indígenas, embora possa ser localizada, como veremos posterirmente, no discurso de algumas lideranças e anciãos.

\section{D) Dificuldades da Escola Karajá}

As dificuldades geralmente apontadas pelos professores nas entrevistas podem ser divididas em dois tipos. $\mathrm{H}$ á aquelas de natureza conjuntural ou quantitativa, que dizem respeito, por exemplo, à escassez de materiais, à precariedade das instalações físicas da escola ou à freqüência insuficiente das supervisões. 0 discurso que privilegia este tipo de caracterização dos problemas geralmente concebe a sua solução em termos de simples ampliação quantitativa:

A principal dificuldade nossa lá é a falta de material, cartilha, caderno, lápis. M eus alunos lá gostam de estudar, a mãe eo pai semprefalam. A dificuldade queelestem ésó Português oral. Setivesse al gum material pra mostrar prá eles ajudava mais. (Julio Lákukui)

0 segundo tipo de problemas está relacionado a fatores mais estruturais, cujo equacionamento requereria mudanças qualitativas, geralmente nem cogitadas pelos professores. Sintomas deste tipo de problemas são caracterizados na fala dos professores em termos, por exemplo, do reconhecimento do alto grau de absentésmo ou da insatisfação da comunidade com o papel por eles desempenhado:

No começo eu tinha 24 alunose agora tenho só 14 , jádesistiram 10 alunos. $0 \mathrm{~s}$ pais acham que a gente está só ganhando dinheiro da Funai ás custas dos alunos. (D aniel $O$ hóri)

As razões apontadas como responsáveis pelas desistências são várias: calendário escolar conflitante com atividades produtivas da comunidade, dificuldades com o português oral, descrença das famílias no ensino bilíngüe, casamento. D e modo geral, a metodologia pedagógica em que foram formados os professores é poupada de críticas. 


\section{A Escola Karajá: as representações da comunidade}

Buscaremos analisar nesta seção outras "vozes" ouvidas e registradas pelos pesquisadores nas al deias visitadas. Entre os anciãos Karajá da aldeia de Santa Isabel, realizaram-se entrevistas com Arutana, Watau, M aluaré e Kutaria. D e modo geral, percebe-se na fala desses antigos líderes Karajá uma profunda nostal gia e um certo conformismo em relação aos rumos que a sociedade Karajá vai tomando. A fala do velho ixydinodu, "chefe ritual" Arutana, é expressiva:

Antigamenteéqueera bom, agora tá prá estragar mesmo. C riançadajánão tá quase querendo saber mais nada do Antigo, só de cidade mesmo. Também fazendeiro bota gado bem aí, turista vem... Antigamente, não. Indio K arajá era guerreiro mesmo. Veio Tori, trouxe coisa da cidade, panela, roupa, agora Karajá precisa...

Embora os velhos sejam ainda muito respeitados e ouvidos pelas lideranças mais jovens, seu prestígio vai ficando cada vez mais restrito às questões de natureza propriamente cultural ou religiosa. Por outro lado, percebe-se que, apesar do saudosismo, os velhos K arajá concordam que é preciso estudar e conhecer o mundo do "branco". N este sentido, não parecem importar-se muito com a discussão sobre o papel da escola na valorização da cultura Karajá. Escola, para eles, não é instituição propriamente Karajá, mas é porta para o "outro lado do rio", a cidade, o mundo Tori:

M eninada tem que ir prá escola, aprender fala deTori, ficar sabido, mas tem algum queesquecequeéK arajá. Antigamente, não... (Arutana)

O utra voz Karajá muito importante é a de Kutaria, filho do velho Wataú, criado para ser guerreiro, na tradição da verdadeira escola Karajá. Kutaria tem dois filhos já rapazes, Ijeseberi e Karirama. 0 primeiro é estudante no segundo grau em um colégio de Goiânia, o segundo mora com ele na aldeia e é mais versado nas tradições Karajá. Sua filha de 14 anos quase não fala Português, bem como o pequenino $M$ axiware, seu filho mais novo, cuja primeira língua é Karajá. Kutaria é mais crítico a respeito da introdução da escola entre os Karajá, mas também não deixa de reconhecer a sua necessidade:

Q uando veio escola, meninadaparou deir prároça, acabou aroçada comunidade Roça bonita quetinha, antigamente. Aí vão práescola, querem ir trabalhar na cidade, largam as coisas dos índios. M as nesses tempos de hoje tem que ter dinheiro prá viver, então precisa ir prá escola mesmo. 
No extremo oposto da escala etária, encontram-se as crianças Karajá, principais beneficiárias da Escola Karajá: meninos e meninas de 6,7, a 14 ou 15 anos, mas principalmente meninos, que povoam as salas de aula nas diversas aldeias e que serão em algum tempo os responsáveis pelos destinos da nação Karajá. A "meninada" constitui uma população crescente em quase todas as aldeias Karajá. São, geralmente, alegres, curiosos e extrovertidos. À exceção daqueles nascidos nas aldeias mais periféricas (Aruanã e Xambioá), todos falam Karajá como língua materna. $\mathrm{N}$ as principais aldeias da I lha do Bananal, visitadas pela equipe, continuam vivas as principais tradições do grupo Karajá. Embora os velhos se queixem do desaparecimento de muitas festas antigas, o principal ciclo ritual - o Aruanã, a dança das máscaras sagradas - continua a ser praticado. N as aldeias de Santa Isabel, Fontoura, Barra do Tapirapé e M acaúba está de pé a heto-krè ou casa-das-máscaras, onde se realiza importante parte da formação dos meninos Karajá e onde se dá a sua iniciação nas tradições religiosas Karajá. 0 ingresso do menino na casadas-máscaras, na categoria inicial denominada de jiurè, é marcado externamente por um corte de cabelo característico. Em todas as aldeias visitadas, encontram-se jiurè, sinal da vitalidade dos sistemas internos de socialização da etnia Karajá.

D e modo gral, as crianças em idade escolar demonstram grande interesse e curiosidade pelas aulas e por tudo que se relaciona à cultura do Tori. Também elas concebem a escola principalmente como veículo de transmissão do saber tori. É comum em todas as aldeias verem-se grupos de jovens viajarem, às vezes, horas de barco ou trator para assistirem às aulas em escolas dos municípios vizinhos, já que nas escolas Karajá podem estudar, no máximo, até a quarta série do primeiro grau. A maior parte desses jovens pensa em conseguir um "emprego", de preferência na Funai, como tratorista, motorista, quem sabe, até chefe de posto. Alguns gostariam de ser professor ou de trabalhar em "escritório". Praticamente todos projetam seu futuro em termos de alguma atividade do mundo tori. Paradoxalmente, poucos dentre eles pensam em deixar suas aldeias. Sorriem, incrédulos, quando lhes indagamos sobre a possibilidade de deixarem para trás sua vida tradicional, sua língua, suas festas. Ficam pensativos quando Ihes contamos que muitos "parentes" nas aldeias de Aruanã e Xambioá já não "brincam" mais o Aruanã e nem falam mais a língua Karajá. Aprenderam a escrever em Karajá, mas não se observa o uso da escrita produtivamente nas aldeias Karajá.

O utro segmento importante da sociedade Karajá é formado por suas lideranças. Estes jovens adultos, geralmente egressos das escolas do 
Peba, vêm tendo cada vez mais um papel decisivo na condução dos interesses do povo Karajá. D urante nossa estadia na aldeia de Santa I sabel do M orro tivemos a oportunidade de entrevistar Ijahuri, um dos mais proeminentes líderes Karajá. Ijahuri Karajá, então ocupando o cargo de superintendente de assuntos indígenas do governo do estado de Goiás, foi candidato a deputado federal pelo PMDB em 1986. Foi aluno do programa de educação bilíngüe organizado pelo SIL e, posteriormente, estudou em escolas secundárias em Goiânia. Já foi chefe do Posto da Funai, na aldeia de Santa I sabel do M orro. É membro da Assembléia de Deus. Em 1985, viajou em companhia do lingüista David Fortune, do SI L, aos Estados U nidos, onde participou de um simpósio sobre literaturas indígenas, em San Antonio, Texas. Presentemente, Ijahuri vive em Goiânia e tem dois filhos, que não falam Karajá. Ijahuri é um entusiasta do ensino bilíngüe intoduzido pelo Peba. D efende o Instituto Lingüístico de Verão de uma das principais críticas que geralmente é feita ao Instituto pelos antropólogos e indigenistas - o proselitismo religioso:

SehojeosK arajátem a suaortografia própria, senóstemos, ou bem ou mal, o ensino na nossa próprialíngua, aalfabetização inicial em Karajá, isso sedeveao Instituto. É claro quemuita coisa ainda precisa melhorar, mas a verdadeéque hojenóstemosumaescola aqui naaldeia, ondeeu eoutras lideranças estudaram diretamenteem Karajá, graças ao Instituto.

Agora, seelestem a religião deles, isso éoutra quetãa. Sefossem marxistas, iriam defender a ideologia marxista. Cada um defende seu ponto-de-vista. (...) Se hojeeu sou protestante, eu não sou menosK arajá por isso, pelo contrario, acho queaprendi aser maisK arajáainda. A C onstituição Brasileiragaranteatodosa liberdadede crençareligiosa...

Ijahuri defende a educação escolar bilíngüe e acredita que a escola tem um papel a desempenhar na luta pela preservação da cultura Karajá. Reconhece a existência de muitos problemas, tais como o abandono a que tem se relegado o sistema escolar Karajá como um todo, mas crê que, como suas bases metodológicas são eficazes, é possível recuperá-lo, sendo necessário apenas que se ampliem os investimentos da Funai no setor educativo. Em uma falta gravada em vídeo para ser exibida aos Karajá de Santa Isabel na TV coletiva da comunidade, Ijahuri exorta as crianças na língua Karajá a estudarem mais, esforçando-se para vencer na vida. Lembra-Ihes que, "assim como o Tori é capaz, também os Karajá podem ir para frente". Cita o seu próprio exemplo, de menino Karajá criado na aldeia e Santa I sabel, hoje ocupando cargo importante na capital. 


\section{As concepções do SIL}

O Instituto Lingüístico de Verão (Summer Institute of Linguistics - SIL) é uma instituição evangélica que tem por finalidade o estudo de línguas ágrafas com vistas à tradução de textos bíblicos, o que é feito pela associada Wycliffe Bible Translators (W BT ). Vem atuando no Brasil desde 1958, ligado inicialmente ao Museu N acional (UFRJ) e, posteriormente, a outras universidades brasileiras. 0 Summer participou direta ou indiretamente da formação de grande parte dos lingüistas brasileiros, especialmente no que diz respeito ao chamado "trabalho de campo", área em que o SIL tem indíscutivel know-how, obtido em mais de 50 anos de atividades junto a quase oitocentas etnias em todo o mundo. A partir de 1969, firma um convênio com a Funai, ampliando seu campo de ação à Educação Indígena. A respeito do modelo de ensino bilíngüe proposto e executado pelo SI L junto a vários grupos indígenas brasileiros, ${ }^{5}$ a União das $\mathrm{N}$ ações Indígenas (U N I), assim se manifestou em documento apresentado em reunião da ONU em Genebra, ${ }^{6}$ em 1985:

A dua adoção integral pela Funai tem seus motivos explicados: daria o ensino bilíngüe com todaa aparência derespeito àlíngua eà cultura, porém conseguiria uma passagem muito maisintegral do índiosao mundo dos brancos, uma vez que todos os valores seriam agora traduzidos na língua nativa e assim muito maisembutidos em suas mentes, pois estavam expressosnos própriostermose modos de concepção indígena.

O SIL designou para atuar junto aos Karajá, a partir de 1958, 0 casal de missionários-lingüistas $\mathrm{D}$ avid e Gretchen Fortune. De acordo com o modelo padrão de trabalho de campo do SIL, estes lingüistas produziram uma primeira análise gramatical de língua Karajá e estabeleceram uma escrita para a língua antes de iniciarem em 1971 o projeto piloto do Programa de Educação Bilíngüe-Bicultural do Araguaia, o Peba. Seus primeiros trabalhos sobre o Karajá filiam-se à Tagmêmica, escola lingüística de cunho estruturalista desenvolvida pelo norte-americano Kenneth Pike, cuja trajetória confunde-se com a do próprio SI L. Posteriormente, os Fortune desenvolveram estudos sobre o Karajá relacionados a outras correntes da Lingüística. Entretanto, não há dúvida de que a parte mais importante de suas pesquisas está ligada à Educação Bilíngüe. Assim, os estudos realizados pelos Fortune revelaram-se perfeitamente adequados para o estabelecimento de um sistema ortográfico e para a produção de material didático bilíngüe, condições básicas para a realização de um programa educacional. Em publicação recente, ${ }^{7} 0$ casal Fortune avalia os resultados do Peba: 
Thedevelopment of a literary-based education has enabled theK arajá to face thechallenges of themid-1980's. In a world of extremely rapid cultural change affecting every major aspect of their society, a major transition has been made. They have managed to retain the values taught in their society in a place of central importance. T hemajority of young $K$ arajá have been taught to read in their mother tongue by bilingual K arajá teachers in their own villages. These newly educated indigenous teachers realised the importance of keeping their own indigenoussystem, which could belost through assimilation. Therefore, they, in words, aptly put,' ... assumed control of education, and economics...and demanded acceptance as a contemporary tribal people' (Scheneider, 1985). Although I djarruri Karajá did not win a seat in theN ational Congress, hewas appointed Coordinator of Indian Affairs for the state of Goiás by the new governor.

Também a professora M argaret $R$. Alford, do SIL, que se juntou à equipe do Peba a partir da segunda metade da década de 1970, publicou uma avaliação ${ }^{8}$ bastante positiva do programa, em que atribui o seu sucesso (sic) aos seguintes fatores:

Theprogrammehas been basically succesful becauseit isculturally relevant in the following ways: a) monolingual Karajá and Portuguese, with bilingual teachersfrom their own culture; b) Karajá writers havebeen trained and have produced culturally and linguistically appropriatereading materialsin mens's and women's speech; c) the first B razilian Indigenous Social Studies book was produced and illustrated by K arajá teachers, showing their world view and ethnic pridein their language and culture.

Infelizmente, a equipe responsável pelo presente projeto não pôde realizar entrevista com o casal Fortune, já que este se encontrava fora do país naquela ocasião. G ravou-se, no entanto, entrevista em vídeo na sede nacional do SIL, Brasília, com o Sr. James Walker, piloto e relaçõespúblicas do Instituto e com 0 casal de lingüistas-missionários $\mathrm{H}$ arold e Frances Popovich, que atua a 30 anos junto aos índios M axakali, tendo amplo conhecimento do projeto desenvolvido pelos seus colegas entre os Karajá. Foram expostas as posições do Instituto a respeito de vários tópicos concernentes à Educação Indígena, em geral, entre os quais o ensino bilíngüe-bicultural:

O sKarajádispõem hojedeuma escolaautenticamentebilíngüeebicultural, de professores próprios, materiais didáticos próprios. Principalmente, através da Educação Bilíngüe obtiveram a possibilidadede, seassim escolherem, transitar entreduas culturas. A travessar a ponte de lá para cá etambém de cá para lá.

A respeito da questão do proselitismo religioso, o sr. Walker expressou o seguinte ponto-de-vista: 
0 que o Instituto faz é colocar à disposição daqueles que quiserem, textos bíblicos em sua língua materna. 0 Instituto considera que um livro como a Bíblia é um patrimônio universal, não é brasileiro, nem norte-americano e, portanto, podeser do conhecimento detodos.

O s membros do SIL referiram-se ainda, durante a entrevista, à necessidade de se dar continuidade ao programa de educação Karajá, de forma a que não se perca o investimento realizado na implementação das escolas Karajá. N este sentido, foi reiterada a disposição do Instituto em cooperar com a Funai, como vinha sendo feito até o final do último convênio Funai/SIL.

\section{As concepções da Funai}

É extremamente difícil apresentar em um texto da natureza do presente relatório uma visão adequada, ainda que sucinta, a respeito das concepções da Funai sobre o Peba. Em primeiro lugar porque é impossível definir no âmbito deste órgão a existência de uma política educacional nítida e consistente em todos os níveis hierárquicos em seus quadros. D evendo, em princípio, atender a cerca de 200 grupos indígenas distintos, o órgão tem, desde sua fundação, adotado sistematicamente a política de delegar parte substancial de suas atribuições no setor educacional a outras instituições.

$\mathrm{N}$ ão raro, instituições missionárias estrangeiras têm sido beneficiárias dos convênios através dos quais se comprometem a "colaborar com a Funai" em programa de educação junto a grupos indígenas brasileiros. A natureza e amplitude desta "colaboração" têm sido amplamente questionadas pela comunidade científica nacional, formulando-se críticas quanto à delegação do dever de tutela, atribuição legal do Estado brasileiro, a instituições estrangeiras. N este sentido, os participantes do Encontro N acional de Educação Indígena, realizado no Rio de Janeiro em 1987, assim se expressaram no documento final do encontro:9

Tendo em vista, portanto, a incapacidadehistória da Funai, queconta hojecom um único profissional deeducação em sua C oordenadoria de Programação e Assessoramento CPA, para desenvover eacompanhar programas educacionais em áreas indígenas e para supervisionar a atuação das agências missionárias, 0 GT recomendaque:

a) continuem suspensos os convênios existentes entre a Funai e as M issões religiosas, não se permitindo o ingresso ea permanência nasáreasindígenas de representantes de agências missionárias queadotem práticas proselitistas, visto serem tais práticas prejudiciaisà integridade cultural dos gruposindígenas; 
b) providenciese a substituição, no menor prazo possível, dos técnicos vinculados á agênciasmissi onárias proselitistas, ainda atuando no Brasil, visandose a redução gradativa da participação daquel es missionários na el aboração e acompanhamento de programas de treinamento ereciclagem de professorese na elaboração dematerial didático para as escolas indígenas;

c) constitua-seuma comissão interinstitucional com vistas aencontrar alternativas para a presente situação de absoluto descontrole da atuação missionária e a implementar mecanismos deação coordenada no campo da educação indígena.

Assim, em função das limitações de recursos humanos e financeiros adequados que, historicamente, têm caracterizado a Funai, o que se verifica é que - via de regra - as instituições conveniadas terminam por exercer uma ingerência quase que total sobre os programas com que, supostamente, estariam colaborando. D essa maneira, percebe-se nitidamente que a equipe Funai/SIL, responsável pela implantação e desenvolvimento do Peba, seria mais autenticamente definida sob o rótulo de equipe "SIL/ Funai", na medida em que é o instituto que estipula as diretrizes básicas do programa e que exerce, de fato, a sua execução, restando à Funai 0 mero papel de auxiliar e legitimar a atuação do SIL.

Além do mais, há que se considerar a conhecida instabilidade ine rente ao órgão tutor. Por exemplo, em 1988, no momento em que realizávamos a pesquisa nas aldeias Karajá, o convênio entre a Funai e o SIL estava suspenso, o que permitiu, como já notamos anteriormente, que outras agências (a própria Funai e a U niversidade Federal Fluminense) pudessem atuar no espaço há 17 anos ocupado exclusivamente pelo SIL. Entretanto, já em 1989, a presidência da Funai restabeleceria o convênio com o Instituto.

N este sentido, que concepções poderia ter a Funai sobre o Peba ou sobre qualquer outro programa educacional? Programas desta natureza têm sido extremamente convenientes para a Funai, que pode apresentar resultados, estatísticas de atendimento, materiais publicados, sem fundamentalmente entrar no mérito dos programas, seja em termos de sua execução ou de sua avaliação. $N$ aturalmente, há na Funai profissionais competentes e dedicados que, eventualmente, obtêm algum resultado por seus esforços sistemáticos e ingentes em algumas áreas de atuação indigenista. E é justamente pela existência desses funcionários que ainda se pode creditar à Funai um mínimo de valor no campo do indigenismo. $M$ as enquanto órgão da burocracia federal, não há como localizar na Funai nenhum critério, nenhum parâmetro consistente que possa ser utilizado na avaliação das representações do órgão a respeito da educação indígena. D e modo geral, tem-se adotado a prática de atribuir ao "órgão 
tutor" a filosofia integracionista, que está explícita em seus estatutos, como pressuposição fundamental subjacente à maioria de suas atuações. Do ponto de vista conjuntural a que nos referimos acima, pudemos verificar a existência, tanto na 6a Superintendência, em Goiânia, quanto na ADR-Araguaia, de profissionais capazes e comprometidos com a elevação da qualidade do ensino oferecido nas aldeias Karajá. D e modo geral, há por parte deste pessoal - programadores educacionais, supervisores, coordenadores, e professores - a concepção de que o índio tem direito legítimo à sua cultura e que os sistemas educacionais organizados para eles devem respeitar este direito. Embora possa parecer o mais óbvio dos truísmos, tal afirmação justifica-se, quando se conhece que o conceito de que "as comunidades indígenas devem ser assimiladas à comunhão nacional" - o velho chavão integracionista-etnocêntrico - é ainda tão vivo no Brasil.

\section{A concepção do Cimi}

O Conselho Indigenista M isionário, órgão ligado aos setores mais progressistas da I greja católica, nunca atuou propriamente entre os K arajá. Estão presentes na aldeia Tapirapé, vizinha à aldeia Karajá de Barra do Tapirapé. $\mathrm{N}$ a aldeia Tapirapé residem as I rmãzinhas de Jesus e desenvolvese um projeto de Educação com o apoio do Cimi. As irmãzinhas, cuja presença na área remonta à década de 1950, chegaram a iniciar um trabalho de assistência aos Karajá que, nesta época, ainda reservavam mais nitidamente suas características de povo nômade, que durante os longos "verões" acampava nas praias do rio Araguaia. As irmãzinhas viajavam de barco pelo Araguaia, indo ao encontro desses grupos para, simplesmente, viver com eles, inculturar-se, aprender sua maneira de ser. Assisti-los no que for preciso, mas sem querer transformá-los, de acordo com os princípios da filosofia "encarnacionista" que adotam.

Em meados da década de 1950, as irmãzinhas assistem à chegada na área dos missionários da M issão N ovas Tribos, a N ew Tribes M ission, cuja atuação missionária tem um caráter marcadamente proselitista. Os missionários das "N ovas Tribos" promoveram a reunião de vários destes grupos nômades, formando a aldeia de $M$ acaúba. As irmãzinhas passaram, então, a dedicar-se exclusivamente aos índios Tapirapé, deixando de trabalhar com os Karajá.

É importante ressaltar-se a diferença entre esses dois tipos de atuação missionária. Abdicar do proselitismo significa não só desistir de converter o 0 utro, introjetando-Ihe valores que acarretarão, em última 
análise, a desestruturação de seu universo próprio, mas implica, igualmente, a adoção de uma atitude solidária para com o 0 utro, no sentido de trabalhar ativamente pelo seu direito a alteridade. N este sentido, a "missão" é de libertação e impõe a co-participação nas lutas do O utro para que este possa afirmar a sua identidade e resistir à descaracterização de sua singularidade pela assimilação aos projetos dos grupos dominantes. Por outro lado, a atuação das agências proselitistas é de "salvação", implicando em última análise, a crença de que o 0 utro não tem um projeto existêncial próprio e que, portanto, deve ser convertido para sobreviver.

A respeito do modelo educacional decorrente da postura não-proselitista, o documento da UN I acima mencionado assim afirma:

Contrapondo-seao modelo SIL, foram surgindo no decorrer dos últimos 10 anos os chamados modelos alternativos. 0 mais amplo é o que vem sendo desenvolvido por pessoas ligadas deum modo ou de outro ao Cimi - Conselho IndígenaM issionário. A questão daformacãa de pessoal vem sendo enfrentada paulatinamente, através do concurso de lingüistas brasileiros, os quais dão cursos intensivos, assessoram projetos, demodo a permitir queosprofessores, geralmente não-índios, aprendam a língua, possam descrevêla e cheguem a um alfabeto. Preferem uma educação, sempreque possível bilíngüe, mas os propósitos são bem diferentes: trata-sedeum processo educacional ligado ao desenvolvimento comunitário evisa, sobretudo, a fornecer os meiosmínimos de defesa parafazer faceà sociedadenacional.

As irmãzinhas avaliam que o Peba fracassou:

0 quefoi que eles conseguiram? Alguns K arajáforam estudar fora, deixaram suas aldeias. M as pelo bem do povo Karajá? O quefoi feito? A própria senhora do D avi (G retchen Fortune) nosfalou umavez queeles haviam falhado. (I rmã Genoveva)

\section{Conclusões}

Esperamos haver esboçado neste artigo os principais fatores que concorrem para caracterizar a Escola Karajá. Seu futuro aprofundamento poderá contribuir para a melhor compreensão da dinâmica sociocultural em que estes índios estão inseridos e, talvez, possa também ajudar na luta desse povo pela afirmação de sua identidade. Q ueremos, a título de conclusão, levantar os seguintes pontos:

1) 0 assessoramento pedagógico aos professores K arajá vem sendo estruturado em novas bases para não se perpetuarem os equívocos decorrentes 
da metodologia do SIL que, como se indicou neste artigo, fundamentase em um bilíngüismo de transição, isto é, utiliza-se da língua e de aspectos da cultura indígena apenas como "ponte" para o ensino do Português e de valores externos, priorizando a realidade do mundo branco e desconsiderando, de fato, os valores intrínsecos da cultura indígena.

2) N a última década, vêm-se procedendo a uma revisão do material didático utilizado nas escolas Karajá. Em sua grande parte, o material produzido pelo SIL contribui para reproduzir junto aos Karajá conceitos e valores que são hoje amplamente questionados na educação em língua portuguesa. Por exemplo, no livro de Estudos Sociais há capítulos como "19 Txu abril", o (o dia do índio), "Biuheòty-txu" (a semana da Asa), "Bandeira - txu" (o dia da Bandeira), que transmitem para os Karajá as mesmas superficialidades, as mesmas "belas mentiras" que se têm hoje tentado mudar na educação nacional.

3) U m projeto educacional de real valor para o povo Karajá não pode ser levado a efeito pela Funai isoladamente, mas deve reunir componentes operacionais provenientes de distintas instituições (governo, universidades, agências não-proselitistas) e não deve restringir-se ao campo educacional somente. D eve-se levar em conta a necessidade de preservação dos ecossistemas da IIha do Bananal, presentemente sob forte ameaça por parte das atividades de pecuária massiva, que ali se desenvolve descontroladamente. Por outro lado, é de fundamental importância trabaIhar em estreita cooperação com os Karajá, no sentido de valorizar a língua Karajá e seus dial etos, bem como a cultura Karajá como um todo, visando não só a sua preservação nos níveis atuais, mas principalmente a sua revitalização, buscando reverter o quadro de desvalorização crescente que ameaça de morte iminente as línguas e culturas minoritárias do Brasil.

Recebido para publicação em agosto de 2000.

N otas

1. M elia, Bartolomeu. Educação e alfabetização indígena. Cimi, 1987.

2. Este projeto teve início em julho de 1983, a partir da solicitação de Lucirene Behederu Javaé, filha do cacique da aldeia do Boto Velho, ao lingüista M arcus M aia e ao antropólogo André Toral, para que estes pesquisadores a assessorassem na alfabetização das 12 crianças daquela comunidade, que nunca havia contado até então com qualquer assistência educacional. Inicialmente patrocinado pela 0 xfam, o projeto passou em 1986 para o âmbito do M useu do Índio, tendo-se elaborado convênio com o D epartamento de Análise M atemática da UFF para assessoramento do ensino da M atemática. 
3. Os seguintes professores indígenas participaram do programa de reciclagem: Antonio Ijoraro, M arvel Tuila e Paulo Krumare (aldeia Karajá de Santa Isabel); D aniel O hòri, D avi Krumare (Aldeia Karajá da Fountoura); Paulo Kuadi (aldeia Karajá de Luciara); Joel Wahuri (aldeia Karajá de Barra do Tapirapé); Raimundo Alàkiri, M arcos Wyra-Wyra e Júlio Làkukui (aldeia Karajá de $M$ acaúba); $M$ aoel M aruaja (adeia Javaé de Kanoano); Valdemir Ixerua e Juarez Tjmari (aldeia Javaé de Barreira Branca); Lucirene Behederu (aldeia Javaé de Boto Velho).

4. Fortune, David and Fortune, Gretchen. Karajá Literary Acquisition and Sociocultural Effects on a Rapidly Changing Culture. Journal of Multilingual and M ulticultural Development, vol. $8, n^{\circ} 6,1987$, p. 488.

5. Apesar de uma curta interrupção do acordo entre a Funai e o SIL entre 1978 e 1983, o SIL continua a trabalhar com cerca de 50 grupos indígenas no Brasil e desenvolve, desde 1970, cinco programas educacionais: Kaingang (1970), Karajá (1971), Xavante (1972), Guajajra (1972) e M axakali (1980).

6. Os Povos Indígenas e o D ireito à Educação no Brasil. D ocumento apresentado pela União das $\mathrm{N}$ ações Indígenas do Brasil na quarta sessão do grupo de trabalho sobre populações indígenas da ONU, em Genebra 1985.

7. Fortune, D avid and Fortune, Gretchen. Karajá literary acquisition and sociocultural effects on a rapidly changing culture. Journal of M ultilingual and M ulticultural D evelopment, vol. 8 , $n^{\circ} 6,1987$, p. 470

8. Alford, M argaret R. A culturally relevant programme for teaching readingin the mother tongue: The Karajá indians of Brazil. Journal of M ultilingual D evelopment, vol. 8, n 6, 1987, p. 493.

9. O Encontro $\mathrm{N}$ acional de Educação Indígena teve lugar no Rio de Janeiro, entre 19 e 23 de outubro de 1987, sob o patrocínio do M useu do Índio e do CNRC da Fundação Pró M emória. Participaram desse Encontro 68 professores, lideranças indígenas, educadores, lingüistas, antropólogos, matemáticos, sociólogos e representantes de entidades civis, instituições científicas e órgãos oficiais, ligados direta ou indiretamente ao campo da Educação Indígena.

\section{Representations on Karaja education}

ABST RACT: This paper reports and analyses different sets of discourse representationson Karaja education produced by indigenousteachers, leaders, as well as government officers and missionariesin an attempt to contribute to the understanding of Karaja bilingual schools.

Key words: Indigenous education; Bilingual education; Indigenous discourse; Karaja; Javaé.

\section{Referênciasbibliográficas}

ALFORD, M argaret R. A Culturally relevant programme for teaching reading in the mother tongue: The Karajá indians of Brazil. Journal of Multilingual Development, № 6, vol. 8, 1987, p. 493.

FORTUNE, David \& G. FORTUNE. Karajá literary acquisition and sociocultural effects on a rapidly changing culture. Journal of Multilingual and Multicultural Development, no 6, vol. 8, 1987, p. 488. 
M ELIA, Bartolomeu. educação e Alfabetização indígena. Cimi, 1987.

OS POVOS indígenas e o direito à educação no Brasil. D ocumento apresentado pela União das N ações Indígenas do Brasil na quarta sessão do grupo de trabalho sobre populações indígenas da ONU, em Genebra, 1985. 